UDC 130.2

LBC 87.52

\title{
TRANSFORMATIONS OF HEGEMONIC MASCULINITY AND FUNCTIONS OF FEMALE IMAGES IN CONTEMPORARY WESTERN FILMS
}

\author{
Ksenia V. Igaeva \\ Minin Nizhny Novgorod State Pedagogical University (Minin University), Nizhny Novgorod, Russian Federation
}

\begin{abstract}
The controversy about modern transformations of consumer society typically is not related to gender studies. At the same time, the spread of mass culture in the consumer society has had a significant impact on the redistribution of gender roles. Gender studies have long been dominated by the study of women's history through criticism of hegemonic masculinity as a system for the distribution of social roles, and economic inequality was only their derivative. Moreover, starting from the first decade of the XXI century, many researchers appear (M. Kimmel, S. Bordeaux, S. Robinson) striving to move away from the established tradition. Thus, according to modern researchers, the concept of "hegemonic masculinity" is controversial. However, it is generally well established in gender studies to describe the power of middle-class white men, their everyday behavior, and normative representations in culture. The purpose of this article is to identify the feedback - the growing influence of the consumption laws, as well as the consumer culture formed on their basis, on the distribution of gender roles in popular Western cinema, which is both a representation and a reinforcement of normative models of social behavior. In modern cinema, the image of a man belonging to the hegemonic type of masculinity undergoes several stylistic changes that allow preserving the former normative ideal. Male images are mimicking in the new social space that has developed in the post-industrial economy, imitating changes in the dominant type of masculinity, which, however, does not lose its power positions. At the same time, the female heroine in popular cinema fails to fundamentally change the established model of normativity: she tries on traditional male roles and becomes a consumer of established stereotypes, refusing to try to change the very system of hegemony.
\end{abstract} studies.

Key words: consumer society, cultural studies, masculinity / femininity, hegemonic masculinity, films, gender

\section{ТРАНСФОРМАЦИИ ГЕГЕМОННОЙ МАСКУЛИННОСТИ И ФУНКЦИИ ЖЕНСКИХ ОБРАЗОВ В ЗАПАДНОМ КИНЕМАТОГРАФЕ КОНЦА ХХ - НАЧАЛА ХХІ ВЕКА}

\author{
Ксения Владимировна Игаева \\ Нижегородский государственный педагогический университет им. Козьмы Минина (Мининский университет), \\ Нижний Новгород, Российская Федерация
}

Аннотация. Полемика о современных трансформациях общества потребления чаще всего не связана с гендерными исследованиями. При этом распространение массовой культуры в обществе потребления оказало достаточно большое влияние на перераспределение гендерных ролей. В гендерных исследованиях долгое время доминировало изучение женской истории посредством критики гегемонной маскулинности как системы распределения социальных ролей, а экономическое неравенство выступало лишь их производной. При этом начиная с первого десятилетия ХХІ в. появляется целый ряд исследователей (М. Киммел, С. Бордо, С. Робинсон), стремящихся отойти от устоявшейся традиции. Таким образом, понятие «гегемонной маску- 
линности» понимается современными исследователями не совсем однозначно. Однако в целом оно достаточно прочно утвердилось в гендерных исследованиях для описания власти белых мужчин среднего класса, их повседневного поведения и нормативных репрезентаций в культуре. Целью данной статьи является обозначение обратной связи - растущего влияния законов потребления, а также сформированной на их основе потребительской культуры на распределение гендерных ролей в популярном западном кинематографе, одновременно являющемся репрезентацией и закрепляющим нормативные модели социального поведения. В современном кино образ мужчины, принадлежащего к гегемонному типу маскулинности, претерпевает ряд стилистических изменений, позволяющих сохранить прежний нормативный идеал. Мужские образы мимикрируют в новом социальном пространстве, сложившемся в постиндустриальной экономике, имитируя изменения доминирующего типа маскулинности, который, впрочем, не теряет своих властных позиций. При этом героине-женщине в популярном кинематографе не удается фундаментально изменить сложившуюся модель нормативности: она примеряет на себя традиционные мужские роли и становится потребителем устоявшихся стереотипов, что не меняет саму систему гегемонии.

Ключевые слова: общество потребления, исследования культуры, маскулинность / феминность, гегемонная маскулинность, кино, гендерные исследования.

Полемика о современных трансформациях общества потребления чаще всего не связана с гендерными исследованиями. Последние критикуют гегемонную маскулинность как систему распределения социальных ролей, а экономическое неравенство выступает лишь ее производной. Целью данной статьи является обозначение обратной связи - растущего влияния законов потребления на распределение гендерных ролей в популярном западном кинематографе, одновременно являющемся репрезентацией и закрепляющим нормативные модели социального поведения.

Как известно, гендерные исследования под разным углом рассматривают концепт маскулинности в современном обществе, начиная с полного перекладывания на мужчин вины за века дискриминации различных социальных меньшинств и заканчивая их оправданием. Известный американский философ Джудит Батлер, рассматривая маскулинность / феминность через призму сексуальности и власти, наделяет мужчину группой властных признаков, из-за которых женщина становится субъектом, нуждающимся в освобождении [Butler 1990]. Австралийский исследователь Р. Коннелл, в свою очередь пишет о том, что не существует единого образа гендерных взаимоотношений и что маскулинность всегда выступает во множественном числе, включает различные типы поведения. Отправной точкой ее исследований становится «гегемонная маскулинность», выражающая интересы белых гетеросексуальных мужчин, находящихся на вершине маскулинной иерар- хии и готовых к ее насильственному поддержанию в обществе [Connell 2005]. Майкл Киммел, в целом соглашаясь с идеей Дж. Батлер в своей работе «Гендерное общество», уточняет, что гегемонной (или доминантной) маскулинностью, обладают лишь мужчины наделенные властью [Киммел 2006]. Американский философ культуры Сьюзан Бордо считает, что мужчины, как и женщины, оказываются вовлечены в институты и практики, которые они не создавали и не контролируют, тем самым пытаясь оправдать доминантное положение мужчин [Bordo 1999]. Таким образом, понятие «гегемонной маскулинности» понимается современными исследователями не совсем однозначно, но в целом оно достаточно прочно утвердилось в гендерных исследованиях для описания власти белых мужчин среднего класса, определяющей их повседневное поведение и нормативные репрезентации в культуре.

В традиционном и индустриальном обществе гегемонная маскулинность ассоциировалась с патриархальным укладом, в котором мужчина должен был обладать высоким социальным статусом, хорошей физической формой, а также демонстрировать покровительское отношение к женщине. Интересно, что эти признаки были отображены в культуpe, а классический голливудский кинематограф был сфокусирован на данном типе маскулинности. Это нашло отражение в таких жанрах как вестерн, боевик, криминальный триллер, романтическая комедия. Герои этих фильмов становились олицетворением реаль- 


\section{НАУЧНЫЕ СООБЩЕНИЯ}

ных людей традиционно-сословного и индустриального общества, таких как рыцарь, ковбой, дворянин-аристократ, белый предприниматель-промышленник, которые обладали всеми признаками, характерными для вышеупомянутого типа. Женщина в кино при этом имела однотипные амплуа в виде объекта вожделения или жертвы, что соотносилось с отсутствием какой-либо социальной и личной самостоятельности всей женской половины общества.

Начиная с 1970-х гг. данный тип маскулинности начинает подвергаться различным испытаниям, таким как женская эмансипация, движения за права цветного населения и гомосексуалистов - все это совпадает с кризисом в экономике, в результате которого многие представители белой гетеросексуальной маскулинности теряют свой высокий социальный статус, власть и финансовую независимость. В рамках постиндустриального общества происходит смена экономической парадигмы, в результате которой появляются новые формы социального взаимодействия, включающие в себя новых участников, ранее находящихся на периферии активной светской жизни (женщины, национальные и сексуальные меньшинства, мужчины низкого социального происхождения). Типичные мужские пространства также претерпевают изменения: шахты, доки, промышленные предприятия с рабочими кабинетами, построенные на века, начинают преобразовывать в мобильные пентхаусы и офисы менеджеров среднего звена. В современном обществе работа перестает быть делом всей жизни, а для построения карьеры требуются новые профессиональные качества, такие как мобильность, уступчивость, гибкость ума, способность подстраиваться под новые социальные условия - все это полностью противоречило гегемонному типу маскулинности.

Таким образом, все чаще гендерные исследователи начинают говорить о кризисе традиционной белой гетеросексуальной маскулинности [Robinson 2000], на смену которой приходят новые формы идентичности [Игаева, Шмелева 2019]. Кинематограф как яркий пример массовой культуры становится частью постиндустриального общества, адаптируясь к новой культурной среде. Изменения традиционных мужских ролей нашли отражение в популярных фильмах современного кинематографа. Филипп Гейтс, анализируя фильмы 1990-х начала 2000-х гг. выделяет целый ряд работ, в которых отразилась экзистенциальная растерянность мужчин среднего возраста, живущих во времена переходной эпохи [Gates 2006]. Голливудский кинематограф в данных условиях либо показывал трагедию мужчин, живущих в новой социальной действительности в таких фильмах как «Шестое чувство», «Неуязвимый», «Магнолия», «Бойцовский клуб», «Красота по-американски», либо иронизировал на эту тему в таких работах как «Американский пирог», «Таинственные люди», «Я, снова я и Ирэн» [Deakin 2012]. Таким образом, был найден консенсус между современным социумом и ролью мужчины в нем.

Первые десятилетия XXI века, завершившие переход к обществу потребления, должны были сформировать мужчину нового типа, окончательно адаптировавшегося к этим социальным рамкам. Современный кинематограф отразил эти перемены в популярном кино, передав главную роль женщине. Но можно ли сделать вывод, что кризис белого гетеросексуального мужчины привел к его кончине?

Для ответа на этот вопрос был проведен анализ четырех произведений кинематографа последнего десятилетия XXI века: американского сериала «Оттенки синего» («Shades of Blue», 2016-2018), британского фильма из 8 серий «Вдова» («Widow», 2019), фильмов героического жанра Marvel - «Капитан Марвел» («Captain Marvel», 2019), «Люди Икс: Темный Феникс» («Dark Phoenix», 2019). Все эти работы появились на экранах примерно в одно время, а их отличительной чертой становится тот факт, что главной героиней является женщина, примерившая на себя классические мужские профессии (детектив, военный, служащий $\mathrm{BBC}$, член отряда спасения).

Сериал «Оттенки синего» повествует о Харли Сантос (Дженнифер Лопес), которой по воле случая приходится примерить на себя две роли. С одной стороны Харли - коррумпированный офицер детективной службы, которая с помощью взяток пытается накопить деньги на учебу дочери. С другой стороны она - информатор ФБР, задачей которого яв- 
ляется уличение офицеров в 64-м отделе в коррупции. При этом чтобы выстоять ей приходится свидетельствовать против своего начальника лейтенанта Возняка (Рей Лиотта), которому офицер Сантос обязана всем: работой, финансовой поддержкой, помощью в ликвидации мужа-садиста. Сам Мэтт Возняк, потерявший ранее дочь, постоянно акцентирует внимание на том, что Харли заменила ее. Главная героиня не одобряет методы работы своего начальника, постоянно пытается сделать шаг навстречу ФБР и сдать его властям, но их слишком сильная эмоциональная связь (граничащая с родственной) мешает ей это сделать.

Второй фильм «Вдова» повествует о женщине, служившей в военном подразделении. Она оставляет свою работу ради семьи (дочери и мужа), но, по стечению обстоятельств, теряет их обоих. При просмотре кажется, что Джорджия Уэллс (Кейт Бекинсейл), сильная женщина, отвечавшая за безопасность своей семьи, была наказана судьбой за то, что выбрала традиционный тип женственности, связанный с сохранением домашнего очага. Увидев в новостях своего погибшего в авиакатастрофе мужа, она решает, что это ее второй шанс на счастье, и отправляется в одиночку в республику Конго на поиски любимого. Фильм постоянно сопровождается флэшбэками главной героини, в которых акцентируется внимание на характеристиках ее мужа: на том, как он много работал и обеспечивал семью, был ее моральной опорой и поддержкой, являлся настоящим главой семьи в традиционном понимании. Но только к концу фильма зритель понимает, что образ, созданный в голове героини, совершенно не соответствует реальности.

Фильмы по комиксам Марвел имеют схожую идею спасения мира от опасности уничтожения. Но вместо популярных в 90-е образов мужчин-героев им на замену приходят женщины. Фильм «Капитан Марвел» повествует о героине Кэрол Дэнверс (Бри Ларсон), служащей в ВВС США, которая в результате крушения самолета попадает на планету Хала, где становится членом разведывательного отряда «Звездная сила». От смерти после крушения ее спасает Йон-Рогг (Джуд Лоу), который пожертвовал для нее свою кровь для переливания и стал ее наставником. На протяжении фильма представления о Йон-Рогге у Кэрол меняются от восторженной идеализации до отрицания. Она понимает, что вся ее новая жизнь - это не то, чего она хочет, но лишь объект желания Другого, который спас ее жизнь после крушения самолета. Несмотря на уличение во лжи своего наставника и разочарование в нем Кэрол так и не смогла оборвать связь между ними и отпускает его. «Люди Икс: Темный Феникс» также повествует о девушке-героине Джин Грей, которая становится жертвой обмана своего учителя профессора Ксавьера. Но гораздо более показательной в этом фильме становится роль другой участницы Людей Икс - Мистик, которая являлась руководителем подразделения отряда спасателей мутантов. В кино явно демонстрируется конфликт интересов между ней и основателем школы профессором Ксавьером, причем выражен он не только в споре между наставником и ученицей, но и между мужчинами и женщинами. Мистик открыто говорит об этом во время их разговора (чем, несомненно, пытается привлечь внимание всего феминистического общества к фильму): «Я не могу вспомнить, когда ты последний раз чем-нибудь рисковал. И, между прочим, женщины столько раз спасали мужчин, что не пора ли поменять название на Женщины Икс?»1.

Эти картины объединяет общая нормативная структура. Во всех фильмах главными героинями являются женщины, которые примеряют на себе мужские роли (Харли Сантес - офицер детективной службы, Джорджия - командир военного отряда в отставке, Кэрол Дэнверс - служащая ВВС США, Мистик - глава подразделения спасателей-мутантов). Все они не только имеют традиционно мужские профессии, но и занимают лидерскую позицию в жизни по сравнению с мужчинами - героями второго плана. Однако ни одна из героинь не принадлежит себе - все они находятся в зависимости от Другого, который определяет ее желания и действия (Мэтт Возняк и Роберт Шталь в «Оттенках синего», Уилл Уэллс в сериале «Вдова», Йон-Рогг в фильме «Капитан Марвел», Чарльз Ксавьер в «Людях Икс»). Т.е. героини фильмов наследуют классическиую модель взаимоотноше- 
ний мужчины и женщины, описанную в философии Лакана, где женщина способна найти свое означаемое только в «другом». Т.е. героини фильмов наследуют классическую модель взаимоотношений мужчины и женщины в философии Лакана, где женщина способна найти свое означаемое только в «другом» [Лакан 2006; 2008]. Кэрол Дэнверс теряет память после крушения самолета и Йон-Рогг нарекает ее новым именем Верс. Теперь ее история плотно связана с жизнью наставника, который, по сути, создает ее заново. То же самое происходит в фильме «Люди Икс: Первый класс» (2011), когда Чарльз Ксавьер встречается с Рэйвен Даркхолм, нарекает ее своей приемной сестрой и называет Мистик. Параллель между жизнью главной героини с жизнью Другого прослеживается и в других фильмах. Например, сильная связь Харли Сантос c ее начальником определяется тем, что он подарил ей жизнь, если выражаться символически. Он решил проблему с ее бывшим парнем, который избивал ее, взял в свой отдел; благодаря Мэтту Возняку она превратилась из брошенной всеми матери-одиночки в детектива 64 округа Харли Сантос, т. е. фактически речь идет о поименовании ее Другим, который в дальнейшем определяет ее поступки и желания. Хотя героиня не хочет быть коррумпированным копом и в последнем сезоне меняет свою судьбу и добровольно садится в тюрьму, она при этом не разрывает связь с Другим, которым выступает Мэтт Возняк. В сериале «Вдова» можно проследить схожий сюжет, который связан с попыткой самоубийства Джорджии и началом ее новой жизни после спасения мужем Уиллом.

Таким образом, голливудский кинематограф как бы «заигрывает» со зрителем, пытаясь продемонстрировать, что традиционно маскулинные черты являются универсальной категорией, которую можно использовать при характеристике любого героя независимо от пола. Эра кино, где женщине было отведено всего две роли: либо быть объектом вожделения, либо жертвой, нуждающейся в спасении, безвозвратно прошла [Жижек 2004]. Также не стоит забывать о целом ряде популярных американских ремейков, в которых женщины не только оказываются в совершенно разных амплуа, но и подменяют классичес- ких героев, которые были мужчинами. Например, американский сериал «Элементарно» не только демонстрирует доктора Ватсона в образе женщины азиатской национальности, но и делает главного злодея всей детективной эпопеи о Шерлоке Хомсе Мориарти любовницей главного героя. Также в этот ряд можно поставить такие образцы голливудской продукции как «Охотницы за приведениями», «Восемь подруг Оушена», «Неудержимые красавицы», «Отпетые мошенницы». И даже гиперсексуальный герой Мела Гибсона в фильме «Чего хотят женщины?» был заменен на героиню-афроамериканку, что свидетельствует о высокой степени толерантности «фабрики грез» к женской половине зрителей и к различного рода меньшинствам. Но, пожалуй, самой ожидаемой премьерой 2020 года является новый фильм об агенте 007 , где главный герой Джеймс Бонд, бывший с 1954 года одним из самых ярких символов гегемонной маскулинности, также заменен героиней-женщиной. Экранизации в новом формате активно привлекают к просмотру женскую аудиторию зрителей, которая в индустриальном обществе не могла активно следить за кинематографическими новинками в силу занятости домашним хозяйством. Таким образом, новые формы социального взаимодействия, сложившиеся в постиндустриальном обществе, дали женщине возможность стать активным потребителем продукции массовой культуры. Кроме того мужчины-потребители также не против подобных ремейков, так как несмотря на расширение социальных ролей женщины в подобных фильмах они не теряют традиционного стремления к демонстрации женской сексуальности на экране. Но несмотря на то, что женщины-актрисы стали занимать большой процент экранного времени, производителями товаров киноиндустрии в подавляющем большинстве продолжают оставаться мужчины, что, безусловно, говорит о сохранении их социального статуса.

Можно сделать вывод, что в популярном кинематографе рубежа XX-XXI вв. образ мужчины, принадлежащего к гегемонному типу маскулинности, претерпевает ряд изменений. При этом героине-женщине не удается фундаментально изменить сложившуюся модель нормативного гендерного поведения: она 
примеряет на себя традиционные мужские роли, становится потребителем устоявшихся стереотипов. Мужские образы мимикрируют в новом социальном пространстве, сложившемся в постиндустриальной экономике, имитируя изменения доминирующего типа маскулинности, который, впрочем, не теряет своих властных позиций. Популярный кинематограф очень быстро улавливает эти тенденции и закрепляет их нормативность.

\section{ПРИМЕЧАНИЕ}

${ }^{1}$ На английском языке школа героев называется «X-Men» - «Люди Икс» или «Мужчины Икс».

\section{СПИСОК ЛИТЕРАТУРЫ}

Жижек 2004 - Жижек C. То, что вы всегда хотели знать о Лакане (но боялись спросить у Хичкока). М.: Логос, 2004.

Игаева, Шмелева 2019- Игаева К.В., Шмелева Н.В. Типология маскулинности в исследованиях моды // Вестник Мининского университета. 2019. T. 7, № 2. С. 15.

Киммел 2006 - Киммел М. Гендерное общество. М.: РОССПЭН, 2006.

Лакан 2006 - Лакан Ж. Имена-Отца. М.: Логос, 2006.

Лакан 2008 - Лакан Ж. Семинары. Изнанка психоанализа 1969-1970. Кн. 17. М.: Логос, 2008.

Bordo 1999 - Bordo S. The Male Body: A New Look at Men in Public and Private. N. Y.: Farrar, Straus and Giroux, 1999.

Butler 1990 - Butler J. Gender Trouble: Feminism and the Subversion of Identity. N. Y., L.: Routledge, 1990.
Connell 2005 - Connell R.W. Masculinities. Berkeley, Los Angeles: University of California Press, 2005.

Deakin 2012 - Deakin P. Masculine Identity in Crisis in Hollywood's Fin de Millennium Cinema. Diss...PhD. The University of Manchester, 2012.

Gates 2006 - Gates Ph. Detecting Men: Masculinity and the Hollywood Detective Film. Albany: State University of New York Press, 2006.

Robinson 2000 - Robinson S. Marked Men: White Masculinity in Crisis. N. Y.: Columbia University Press, 2000.

\section{REFERENCES}

Zhizhek S., 2004. What you always wanted to know about Lacan (but were afraid to ask Hitchcock). M., Logos.

Igaeva K.V., Shmeleva N.V., 2019. Typology of masculinity in Fashion Studies. Vestnik of Minin University, vol. 7, no. 2, p. 15.

Kimmel M., 2006. Gender society. M., ROSSPEN.

Lacan J., 2006. Names-of the Father. M., Logos.

Lacan J., 2008. Seminars. The reverse side of psychoanalysis 1969-1970. Book 17. M., Logos.

Bordo S., 1999. The Male Body: A New Look at Men in Public and Private. N. Y., Farrar, Straus and Giroux.

Butler J., 1990. Gender Trouble: Feminism and the Subversion of Identity. N. Y., L., Routledge.

Connell R.W., 2005. Masculinities. Berkeley, Los Angeles, University of California Press.

Deakin P., 2012. Masculine Identity in Crisis in Hollywood's Fin de Millennium Cinema. Diss...PhD. The University of Manchester.

Gates Ph., 2006. Detecting Men: Masculinity and the Hollywood Detective Film. Albany, State University of New York Press.

Robinson S., 2000. Marked Men: White Masculinity in Crisis. N. Y., Columbia University Press.

\section{Information About the Author}

Ksenia V. Igaeva, Researcher, Minin Nizhny Novgorod State Pedagogical University (Minin University), Ulyanova St, 1, 603002 Nizhny Novgorod, Russian Federation, igaeva.ksenia@yandex.ru, https://orcid.org/0000-0002-8581-0015

\section{Информация об авторе}

Ксения Владимировна Игаева, научный сотрудник, Нижегородский государственный педагогический университет им. Козьмы Минина (Мининский университет), ул. Ульянова, 1, 603002 Нижний Новгород, Российская Федерация, Igaeva.ksenia@yandex.ru, https://orcid.org/0000-0002-8581-0015 